\title{
Structure and functions of yellow-breasted boubou (Laniarius atroflavus) solos and duets
}

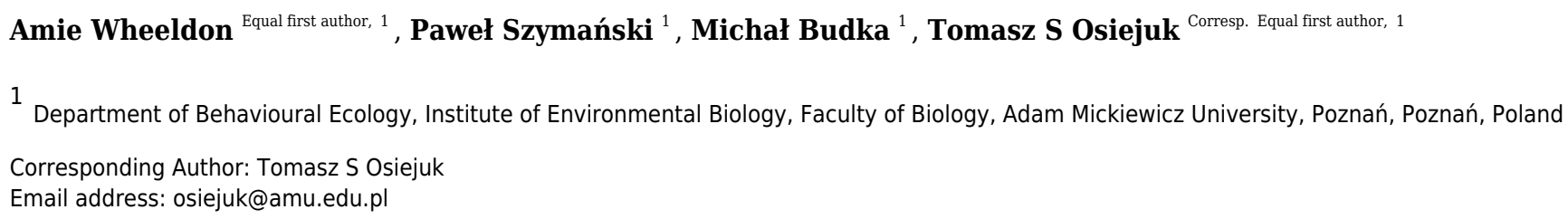

Background. Birds have an extremely well-developed acoustic communication and have become popular in bioacoustics research. A majority of studies on bird song have been conducted in the temperate zones where usually males of birds sing to attract females and defend territories. In over 360 bird species inhabiting mostly tropics both males and females sing together in duets. Avian duets are usually formed when a male and female coordinate their songs. We focused on a species with relatively weakly coordinated duets, with male solo as the prevailing vocalisation type. Methods. Instead of analysing a set of recordings spread over a long time, we analysed whole day microphone-array recordings of the Yellow-breasted Boubou (Laniarius atroflavus), a species endemic to West African montane rainforests. We described the structure of the solo and duet vocalisations and temporal characteristics of daily activity based on 5,934 vocal bouts of 18 focal pairs and their neighbours. Results. Birds had small, sex specific repertoires. All males shared three types of loud whistles functioning as song type repertoires in both solos and duets. Females vocalised with five types of harsh, atonal notes with a more variable and usually lower amplitude. Three of them were produced both as solos and in duets, while two seem to function as alarm and excitement calls given almost exclusively as a solo. Solos were the most common vocalisation mode $(75.4 \%)$, with males being more vocally active than females. Duets accounted for $24.6 \%$ of all vocalisations and in most cases were initiated by males (81\%). The majority of duets were simple $(85.1 \%)$ and consisted of a single male and female song type, but altogether 38 unique duet combinations were described. Males usually initiated calling at dawn and for this used one particular song type more often than expected by chance. Male solo and duet activities peaked around dawn, while female solos were produced evenly throughout the day. Discussion. Yellow-breasted Boubous is a duetting species in which males are much more vocal than females and duetting is not a dominating type of vocal activity. Duet structure, context and timing of daily production support the joint resource defence hypothesis and mate guarding/preventing hypotheses, however maintaining pair contact also seems to be important. This study provides for the Peer) reviewing PDF | (2020:06:50332:1:2:NEW 14 Aug 2020) 
first time the basic quantitative data describing calls, solos and duet songs in the Yellowbreasted Boubou. 
1

\section{Structure and functions of Yellow-breasted Boubou}

3 (Laniarius atroflavus) solos and duets

6 Amie Wheeldon ${ }^{1}$, Paweł Szymański ${ }^{1}$, Michał Budka ${ }^{1}$, Tomasz S. Osiejuk ${ }^{1}$

$8{ }^{1}$ Department Behavioural Ecology, Institute of Environmental Biology, Faculty of Biology,

9 Adam Mickiewicz University, Poznań, Poland

11 Corresponding Author:

12 Tomasz S. Osiejuk ${ }^{1}$

13 Department Behavioural Ecology, Institute of Environmental Biology, Faculty of Biology, Adam

14 Mickiewicz University, Poznań

15 Uniwersytetu Poznańskiego 6, Poznań 61-614, Poland

16 Email address: osiejuk@amu.edu.pl or t.s.osiejuk@life.pl

17 


\section{Abstract}

19 Background. Birds have an extremely well-developed acoustic communication and have

20 become popular in bioacoustics research. A majority of studies on bird song have been

21 conducted in the temperate zones where usually males of birds sing to attract females and defend

22 territories. In over 360 bird species inhabiting mostly tropics both males and females sing

23 together in duets. Avian duets are usually formed when a male and female coordinate their

24 songs. We focused on a species with relatively weakly coordinated duets, with male solo as the

25 prevailing vocalisation type. Methods. Instead of analysing a set of recordings spread over a

26 long time, we analysed whole day microphone-array recordings of the Yellow-breasted Boubou

27 (Laniarius atroflavus), a species endemic to West African montane rainforests. We described the

28 structure of the solo and duet vocalisations and temporal characteristics of daily activity based on

295,934 vocal bouts of 18 focal pairs and their neighbours. Results. Birds had small, sex specific

30 repertoires. All males shared three types of loud whistles functioning as song type repertoires in

31 both solos and duets. Females vocalised with five types of harsh, atonal notes with a more

32 variable and usually lower amplitude. Three of them were produced both as solos and in duets,

33 while two seem to function as alarm and excitement calls given almost exclusively as a solo.

34 Solos were the most common vocalisation mode (75.4\%), with males being more vocally active

35 than females. Duets accounted for $24.6 \%$ of all vocalisations and in most cases were initiated by

36 males $(81 \%)$. The majority of duets were simple $(85.1 \%)$ and consisted of a single male and

37 female song type, but altogether 38 unique duet combinations were described. Males usually

38 initiated calling at dawn and for this used one particular song type more often than expected by

39 chance. Male solo and duet activities peaked around dawn, while female solos were produced

40 evenly throughout the day. Discussion. Yellow-breasted Boubous is a duetting species in which

41 males are much more vocal than females and duetting is not a dominating type of vocal activity. 
42 Duet structure, context and timing of daily production support the joint resource defence

43 hypothesis and mate guarding/preventing hypotheses, however maintaining pair contact also

44 seems to be important. This study provides for the first time the basic quantitative data

45 describing calls, solos and duet songs in the Yellow-breasted Boubou.

\section{Introduction}

Birds have an extremely well-developed form of acoustic communication and so have become

one of the most popular models in bioacoustics studies (Catchpole \& Slater, 2008). The

overwhelming majority of studies on bird song have been conducted in the temperate zone, a

region in which only a small proportion of bird species breed (Riebel et al. 2019). Such research

has been neglected in the tropics which is a region where extremely high bird biodiversity is

incorrect definition of bird song - an elaborate vocalisation produced by males during the

breeding season to attract mates and defend territories (Catchpole \& Slater, 2008). However, recently Odom et al. (2015) showed that female song performance is much more common than once thought, especially in the tropics, and was likely ancestral in oscine species (Odom et al., 2014). Although many songbirds are now classified as having female song, not many are truly monomorphic in singing (Garamszegi et al., 2005) with both male and female songs varying in acoustic rate, structure and complexity (Price, 2015). What is more, in many songbirds males and females sing together. Duetting can be described as vocalisations initiated by an individual that has a consistent time lag between the vocalisation of another individual, with this pattern being reproduced in the same way over time (Langmore 2002). In summary, duetting is essentially a collective behaviour consisted of initiation by an individual and response of vocalisations by a different individual (Logue \& Krupp, 2016). Duetting has been described for over 360 species 
66

67 68

69

across 50 different families of passerines and non-passerines (Hall, 2009). Despite the growing interest in female song and duets, and the vast reviews on functions (Hall 2009), there can be further for specific species, thereby adding to the general repertoire of knowledge being created (Dahlin \& Benedict, 2014).

Research on duetting in birds has led to the formulation of many hypotheses trying to explain their functions. The historical development of these hypotheses was shown in a very detailed reviews by Hall $(2004,2009)$. It was described that birds can gain different types of information through information conveyed to different receivers (partner, rivals or even predators) and this has evolved under cooperative or conflicting situations between partners (Hall, 2004). As a result, these hypotheses have diversified the potential for a general explanation of duetting evolution and functionality. Moreover, many different functions are not mutually exclusive and there may be a diverse use of duets in different species (Hall, 2004). For example, the sex recognition function (Hooker \& Hooker, 1969) may in fact act as a prerequisite for maintaining contact, synchronisation of reproduction, territory defence and so on. We do not want to repeat and discuss all the possibilities, but rather indicate the most promising explanations which seem to be important for the study species. Maintenance of contact between paired individuals using duets was found in habitats with dense vegetation and was one of the earliest functions proposed (e.g. Thorpe \& North 1966; Lamprecht et al., 1985; Logue, 2005). Duetting for maintenance of contact should occur all year round (Odom et al., 2017), whereas, if duets are used for reproductive synchrony, as suggested by Dilger (1953), there should be a peak in activity around the nest building phase (e.g. Topp \& Mennill, 2008). Mate guarding behaviour which clearly involves a conflict situation - can also utilise duetting behaviour. If an individual responds to its partner in a duet it advertises its mated status. Individuals can also 
89 answer a mate to guard paternity and deter rival males, as seen in male Rufous-and-white Wrens

90 (Thryophilus rufalbus; Kahn et al., 2018). Another explanation related to a conflicting situation

91 is signal jamming avoidance, which was experimentally shown to determine structure of duets in

92 one of the pair-living antbird species (Hypocnemis peruviana; Seddon \& Tobias, 2009). The

93 other group of proposed duet explanations belongs to the joint resource defence hypothesis,

94 which assume that mated birds defend some resources, like a territory, together against outsiders

95 (Seibt \& Wickler, 1977). As with the aforementioned functions, one can expect a variety of male

96 and female signalling strategies related to their locations, fighting abilities or mated status. For

97 example, male and female birds may respond stronger to the same-sex intruder (Logue, 2005) or

98 with equivalent intensity to both sexes like in Barred Antshrikes (Thamnophilus doliatus)

99 (Koloff \& Mennill, 2013). Several hypotheses are more or less directly related to the fact that

100 duetting behaviour is more often found in tropical birds than temperate species. Therefore,

101 explanations for duetting are largely based on the differences between temperate and tropical

102 birds' biology (Hall, 2009). Surprisingly, a recent broad-scale phylogenetic comparison revealed

103 duetting evolved in association with the lack of migration, but not with sexual monomorphism or

104 breeding in the tropics (Logue \& Hall, 2014). Thus, despite increasing number of studies on

105 duetting birds, there is still a great need for basic duetting data for unexplored species.

106 One of the relatively well studied families of birds, with regards to duetting behaviour,

107 are the bush-shrikes (Malaconotidae). These exclusively African birds are usually resident and

108 are highly territorial, with a monogamous breeding system (Harris \& Franklin, 2010), thus

109 evolved under ecological conditions promoting the evolution of coordinated defence of resources

110 (Logue \& Hall, 2014). Among bush-shrikes, the most abundant is the genus Laniarius with 22

111 species. The majority of Laniarius species are monomorphic in colour, with the exceptions 
112 differing slightly in colour with paler females, (Harris \& Franklin, 2010) and utilise a skulking

113 behaviour using their loud calls as the main sort of communication (Sonnenschein \& Reyer,

114 1984). The Tropical Boubou (Laniarius aethiopicus), Crimson-breasted Gonolek (Laniarius

115 atroccineus) and Slate-coloured Boubou (Laniarius funebris) have all been described as using

116 duets for territorial defence and mutual mate guarding (Grafe \& Bitz, 2004a; van den Heuvel,

117 Cherry \& Klump, 2014; Sonnenschein \& Reyer, 1984). Although bush-shrikes have a relatively

118 small acoustic repertoire they can alter the various parameters of their songs, such as the

119 repetition of a note or the pitch, in order to produce more complicated or more simple duets

120 (Harris \& Franklin, 2010). Grafe, Bitz \& Wink (2004) explain that the Tropical Boubou may

121 have a more precise way of communication due to the large number of duet types in its

122 repertoire, compared to other boubou species.

123 The formulation of hypotheses that allow for unambiguous testing of duet functions

124 requires prior knowledge of natural song variation. Hence, the use of vocalisations obtained

125 through natural, unprovoked settings provides a baseline for the standard behaviours and can be

126 used as a guide for further experiments (Mennill \& Vehrencamp, 2008). Therefore, in the first

127 step of our wider study we describe (1) the various vocalisation types produced by male and

128 female Yellow-breasted Boubous (Laniarius atroflavus) and (2) we analyse how particular types

129 of vocalizations are used as a solo or as part of a duet. Then, (3) we try to indicate the potential

130 functions of the different vocalisation types based on natural vocalisation patterns. This is for

131 vocalisations produced during within- and between-pair interactions. We used recordings from

132 microphone arrays which allow for the analysis of whole day interactions between neighbouring

133 pairs in the peak of the breeding season. The present study will increase the knowledge of

134 duetting behaviours in a relatively well studied group of species. However, the adding of data on 
135 a new species adapted to live in a mountain rainy forest (Fry, 2020a), should help to better

136 understand factors affecting evolution of duetting in Laniarius species.

137

\section{8}

139

140

141

142

143

144

145

146

147

\section{Materials \& Methods}

The Yellow-breasted Boubou is a sexually monochromatic (likely human perception only, see Osinubi et al., 2018) and socially monogamous bush-shrike, endemic to the montane forests of south-eastern Nigeria and western Cameroon (Stuart 1986; Borrow \& Demey, 2001; Fry, 2020a). Pairs inhabit dense undergrowth at the edge of clearings, secondary scrubs, small forest remnants and bamboo highlands above 1500 m above sea level (Riegert, Přibylová \& Sedláček, 2004) in which they hold year-round territories. On Mount Cameroon Yellow-breasted Boubous can also be found at lower elevations, from $700 \mathrm{~m}$ above sea level (Fry, 2020a). While there has been a description of Yellow-breasted Boubou vocalisations (Riegert, Přibylová \& Sedláček, 2004; Fry, 2020a), little is known about their function or the context in which they are produced. It merely informs us about how they sound rather than what the vocalisations mean or in what context they are produced. Both males and females produce solos as well as initiate duet bouts. They are vocally active throughout the year, but with a clear peak that starts at the beginning of the dry season (late November - January; Olszowiak, 2018; A Szymański et al., unpublished data).

Study area and population. Our study area was located in the Bamenda Highlands, near to Big Babanki village in the Northwest Region of Cameroon $\left(6^{\circ} 5^{\prime}-6^{\circ} 8^{\prime} \mathrm{N}\right.$ and $10^{\circ} 17^{\prime}-$ $10^{\circ} 20^{\prime}$ E). The study area was covered by approximately $12 \mathrm{~km} 2$ of montane habitat (from 1900 to $2400 \mathrm{~m}$ above sea level). The Bamenda Highland region is one of the most important hotspots of bird diversity and endemism in Africa but, due to intensive logging in recent decades, the formerly continuous forests have been reduced to isolated patches (Orme, et al. 2005; Reif et al., 
159 2006). During the study, the habitats within the study area were a mosaic of montane forest

160 patches, shrubby corridors and grasslands, with vegetable plantations below $1800 \mathrm{~m}$ above sea

161 level. The study species was common in this area and was found inside larger forest patches, as

162 well as in smaller remnants along streams. In these areas its population was continuous, and the

163 Yellow-breasted Boubou vocalizations were one of the most common signals heard (Reif et al.,

164 2006). Detailed characteristics of the habitats in the study area is presented in Budka et al.

165 (2020).

166 The study was conducted at the beginning of the dry season (November-December), a

167 time when most bird species in this region start to breed (Serle, 1981; Tye, 1992; Sedláček et al.,

168 2007). During this period, we observed boubous building nests, laying and incubating eggs, and

169 adult birds with young. Our own observations suggest that the breeding period may start at the

170 beginning of November but that it can be elongated, as brood losses are quite common and so

171 pairs may attempt to breed multiple times.

172

Microphone array recordings. In 2014 (from 12 November to 5 December) we

recorded birds with eight automatic recorders (Song Meter SM3 connected with dedicated GPS

receivers; Wildlife Acoustics) organised into a microphone array. Recorders were put on trees in such a way that their microphones had active ranges covering the territories of up to three focal

177 pairs whilst also recording their adjacent neighbours. From our own recordings that cover a 24

178 hour period, we know that this species only incidentally produce vocalisations at night (own

179 unpublished reconnaissance material; 16 points recorded continuously 48 hrs with SM1 Wildlife

180 Acoustics song meters in 2010). Therefore, all recorders were synchronised ( \pm 1 ms accuracy) by

181 the GPS in such a way that they started recording at 05:00 (sunrises were between 06:06 and 
182 06:14) and stopped recording at 19:00 (sunsets were between 17:58 and 18:01). This recording

183 regime allowed us to obtain the entire vocal activity of the Yellow-breasted Boubou pairs. SM3

184 units recorded single channel soundscape with $48 \mathrm{kHz}$ frequency sampling and 16 bits quality.

185 Altogether we collected array recordings for 18 focal pairs, covering eight separate areas,

186 producing a whole day activity recording using an eight-channel microphone array setup (see

187 Figure S1). In each of the eight areas we recorded 1-3 focal pairs bordered with 1 or 2 recognised

188 neighbours. We used an 8-channel microphone array to simultaneously record 3 pairs in 3

189 sessions, 2 pairs in 4 sessions and 1 focal pair in 1 session. These numbers reflected natural

190 locations and sizes of particular territories and made it possible to place the microphones in a

191 specific way so we could assign a particular channel(s) to a particular pair, based on the highest

192 amplitude. If focal pairs produced vocalisations, they were always recorded on three or more

193 channels within the microphone array.

\section{Definitions used for describing vocalisations and sound analysis. Bird vocalisations}

are traditionally divided into songs and calls, and songs are usually louder and longer than calls and are involved in mate attraction and territory ownership (Catchpole \& Slater, 2008). simple and are not intuitively easy to classify into one of these two separate categories. Based on scarce literature data, our own preliminary observations and recordings, we tried to use song and call terms, together with the naming of vocalisations based on their structure in an onomatopoeic way (referring when possible to Fry, 2020a). In further terminology, describing vocalisations and 
205 - call - short and simple vocalisation, usually used in specific contexts such as alarm, begging;

206 etc.;

207 - song - vocalisations used for advertising mate or territory ownership;

208 - phrase - unit within a song, which may be an element (uninterrupted trace on sonogram) or set

209 of elements occurring together;

210 - call bout and song bout - continuous call or song phrase output, where calls or phrases are

211 separated by a silent interval (gap) lasting substantially longer than intervals between calls or

212 phrases within the bout;

213 - call type and phrase type - version of call or song phrase, which could be defined on the basis

214 of a specific (repeatable among individuals) structure;

215 - duet - coordinated singing by male and female so that their phrases alternate or overlap; in the

216 study species duets usually consist of two or more phrases and form a duet bout, the equivalent

217 of a 'duet train' like male-female-male-female etc. (Brown \& Lemon, 1979);

218 - duet type - particular combination of the phrase types used by duetting birds;

219 - solo - song bout consisting of a single or a series of phrases produced in a sequence by one

220 individual and separated from its other vocalisations by a substantially longer time than intervals

221 within the bout; for the study species the same phrase types were used for solos and duets and so

222 our definition of solo is equivalent to that proposed by Logue \& Krupp (2016) which is the

223 initiation of a duet which remained without answer.

224 Each call and song bout can be characterised by its: duration (s), number of units (calls or 225 phrases) produced by a male, female or both sexes and rate (units / min). For duets one may also

226 calculate sex bias - defined here as a ratio of female to male phrases in a single duet bout. Sex

227 bias reflects the contribution of a particular sex to a duet train (Logue \& Krupp, 2016). 
228 Recognition of individuals. Assignment of vocalisations recorded of particular pairs was a multi-

229 step process. First, one person (AW) assigned each vocalisation bout to a particular song or call

230 type category and to a particular pair (or non-focal neighbour) based on the highest amplitude on

231 a particular channel (see Figure S1). A simple map showing locations of each recorder (and

232 respective channel on multi-channel file) in relation to territories position was used as an aid. For

233 the majority of cases there was no problem as birds called from known positions within their

234 territories and usually for a short time of a few seconds or for a few minutes (depending on the

235 time during the day), with neighbours responding from their own positions. Birds from outside

236 the recorded area appeared on a single (edge) channel and were easy to recognize as non-focal

237 birds, due to the low amplitude presented on the array channels (see Figure S1). In addition, a

238 second person (TSO) was checking all identified bouts and in case of any doubts pointed by the

239 first person was checking, in detail, characteristics of a particular bout. Doubts appeared usually

240 because of the quality of songs, e.g. when target sound overlapped with signals of other species.

241 With male song phrases it was easy, despite a fully shared repertoire, to assign particular

242 individuals as each male song from a particular category has its individual specificity reflected

243 by small but consistent differences in frequency and duration. This time-frequency characteristic

244 of male calls was already used in a methodological study on measuring individual identity in

245 general (Linhart et al., 2019). We compared the shape of phrases with the Peak Frequency

246 Contour measurement of Raven Pro with measurements visible on screen and listening to the

247 signal with slow speed. In case of doubts because of quality we also used measurements of

248 frequency and time in order to compare phrases directly with earlier recordings of recognised

249 males (Fig. 2). Please notice, that for each session we only need to discriminate between a

250 maximum of three focal males and 1-2 additional neighbours (assigned only to the category non- 
251 focal pair). To our knowledge it is not possible to discriminate between females based on their

252 simple time-frequency characteristics of songs (personal observations). Therefore, for female

253 solos we assigned bouts solely based on the location in which they were produced. In such cases

254 the preceding and followings bouts of neighbours or their own partner, make such assignments

255 certain. Hence, the main potential error in our dataset may be a result of singing by focal females

256 from outside of their own territories and assignment of such bouts to other pairs or non-focal

257 birds. However, based on our observations of colour-ringed birds we assume that such cases, if

258 any, were extremely rare (personal observations).

259 Sound analyses were done in Raven Pro v. 1.5 (Cornell Lab of Ornithology, Ithaca, NY;

260 http://www.birds.cornell.edu/raven). All eight channels of the microphone array recordings were

261 visually inspected (with auditory examination if necessary) and all call and song bouts were

262 selected within the channel with the highest signal amplitude which came from the recorder

263 placed in the song activity centre of a particular territory. Additional annotation columns were

264 added to each recording in a standard way and, as a consequence, each selection containing a

265 bout included the following information: time of the start and end (actual and in relation to

266 sunrise and sunset time), category of bout (call, solo or duet), sex of initiator, type and number of

267 units produced by each sex, pair identity (based on location and individual call characteristics)

268 and additional notes.

At this stage all calling bouts were selected from recordings and the following parameters

270 of Raven Pro were used: Window type: Hann, 1024 samples; 3 dB Filter Bandwidth: 67.4 Hz;

271 Time grid: overlap 50\% giving Hop Size: 512 samples; Frequency Grid: DFT Size: 1024

272 samples giving $46.9 \mathrm{~Hz} \times 10.7 \mathrm{~ms}$ resolution of measurements. 
275

276

277

278

279

280

281

282

283

284

285

286

287

288

289

290

291

292

293

294

295

296

297

solos, as well as duets, basic descriptive statistics were used. We focused on the frequency of different vocalisation bouts produced by focal pairs, and quantified them by the number of phrases, duration and rate. In order to characterise the general daily pattern of vocalising we counted the number of different bout classes (e.g. call bouts, solos, duets etc.) produced by each pair during every hour of activity and with reference to the time of sunrise. In addition to descriptive statistics, we used generalized mixed models (GLMM) with a log-link function and Poisson error distribution, or identity link function and Gaussian error distribution, that included pair identity as a random factor, with time of day (hour in relation to sunrise), type of bout (solo, duet), sex (male, female) and duet initiator (male or female) as explanatory effects. All statistical analyses were performed using the program STATA/MP 16.x (StataCorp, College Station, Texas, USA). Mean $\bar{x} \pm$ SE values and 95\% CI are reported.

Ethical approval. This study has exclusively observational character, and due to national law for this type of study formal consent is not required (The Act on Experiments on Animals (Disposition no. 289 from 2005). However, it was part of a wider project which as a whole was approved by the Local Ethical Committee for Scientific Experiments on Animals permit no. 16/2015, and Polish Laboratory Animal Science Association 1952/2015 certificate to TSO.

\section{Results}

Sound material analysed. In total, eight whole day recording sessions were analysed with 1-3 focal pairs recorded simultaneously ( $\mathrm{N}=18$ pairs). This produced nearly $900 \mathrm{hrs}$ of single channel recordings in which we found 5,934 call and song bouts which contained a total of 88,442 calls and song phrases. Among those bouts, 4,753 (80\%) were assigned to the 18 focal pairs, while 1,181 (20\%) were considered as being produced by neighbours from adjacent 
298 territories outside the microphone array based on their appearance on particular channels of the 299 recording.

300 Types of call and song bouts produced. As many as $75.4 \%$ of all bouts recorded $(\mathrm{N}=$ $3014,472)$ were produced by a male $(63.2 \%)$ or by a female $(36.8 \%)$. However, among female solos 302991 bouts ( $16.7 \%$ of all bouts) were call bouts or non-song vocalisations (more details below); 303 duets accounted for $24.6 \%(\mathrm{~N}=1,462)$ of all bouts. We found that the phrases of males and 304 females produced in solos and duets were easy to categorise to a limited number of classes based 305 on audio detection and visual inspection of spectrograms.

Male solos. Males produced three whistle phrase types named High whee-oo, Low wheeoo and Hwee-hwee (Fig. 3). We found very consistent and statistically significant differences in proportions of these three phrase types used by all males as solos (GLMM, $\beta \pm \mathrm{SE}=-0.21 \pm$ $0.014 ; z=-14.75, p<0.001)$. High whee-oo were produced the most often $57 \pm 2.3 \%(95 \% \mathrm{CI}$ :

$31052.2-61.4 \%$ ), then Low whee-oo $28 \pm 1.8 \%$ (95\%CI: 24.3-31.5\%), and Hwee-hwee $15 \pm 1.2 \%$

311 (95\%CI: 12.8-17.8\%).

312 Female solos. Female vocalisations had a completely different acoustic structure, being 313 atonal, harsh notes of differing durations. Most of them were classified as Keck (59.1\%), Chock314 series (32.5\%), Chock (3.8\%) and Kee-roo (3.5\%) with very few examples of Rasp (1.1\%) (Fig. 315 4). Kecks were rattle-like calls exclusively produced in a high rate series consisting of up to 316 hundreds of single and very short notes. Visual observations clearly suggest that Kecks were 317 produced in an alarm context, e.g. close to the nest. Chock-series were always produced as a 318 series of 2-14 calls with a high rate, almost without gaps between phrases $(0.8-0.15 \mathrm{~s})$ and with 319 up to 14 phrases in a row. Chocks had a similar but distinguishably different structure to chock320 series, and were produced as a single, double or triple-unit as one phrase after another but 
321 without consistent spacing in time, apparently different to the characteristics for the Chock-

322 series. Rasps were very rarely produced (recorded only 33 times) and to our knowledge they are

323 given in the context of high excitation (personal observations). Rasps were also relatively quieter

324 in comparison to the other vocalisations, and because of that might, on occasion, have not been

325 recorded. Therefore, we did not include them in most of the analyses. Based on both array

326 recordings and observations of vocalising birds we cannot state that Kecks and Rasp calls are

327 also produced by males.

328 Unlike males, the proportions of phrase types (Chock-series, Chocks and Kee-roos) used

329 for solo singing were very variable (GLMM, $\beta \pm \mathrm{SE}=-0.29 \pm 0.054 ; z=-5.44, p<0.001$ )

330 among females from the 18 focal pairs. Chock-series were the most commonly observed call

331 type among female solos: $71 \pm 8.7 \%(95 \% \mathrm{CI}$ : 53.8-88.0\%), then Kecks $16.8 \pm 8.2 \%(95 \% \mathrm{CI}$ :

$3320.3-33.4 \%)$, Kee-roos $12.2 \pm 4.3 \%$ (95\%CI: 3.1-20.7\%) and finally Chocks 5.6 $\pm 2.7 \%$ (95\%CI:

$3330.01-10.98 \%$ ). If we consider female notes classified as functional calls, Kecks were commonly

334 used by all females $98.1 \pm 0.01 \%$ (95\%CI: 96.6-99.7\%) while Rasps were found $1.9 \pm 0.7 \%$

335 (95\%CI: 0.33-3.39\%) incidentally.

336 Duets. Yellow-breasted Boubous used the same phrase types for duetting as were used

337 for solo vocalisations. Among 1,462 analysed duetting bouts, $85.1 \%$ were simple duets

338 consisting of a single type of both male and female phrases. In $81 \%$ of cases duets were initiated

339 by males and in $19 \%$ by females, however, even if a female initiated a duet, she usually reverted

340 to following the male components of a duet. Even in duets where female phrases prevail over

341 male phrases, female phrases were organised in time in relation to male elements which were

342 always produced with a very constant rate (Fig. 5). The most typical male initiated duets used

343 High whee-oo phrases (52\%) then Low whee-oo (38\%) and finally the Hwee-hwee phrase type 
$344(10 \%)$. Female initiated duets most often used the Chock-series (42\%), Kee-roo (35\%) and

345 Chock (20\%) phrase types (Table S1).

346 When we focused on duets produced by the 18 focal pairs, we found that only one duet

347 type was found in the repertoire of all pairs. It was initiated by females with Chock-series, then

348 males produced High whee-oo and females overlapped these phrases with Kee-roo. Another few

349 duet types which were common and found in repertoires of majority of pairs were also simple in

350 structure and consisted of a single male and female phrase produced with time overlap. We

351 found 16 duet types produced only once by a single pair and their uniqueness was that in a single

352 duetting bout male and/or female switched between different phrase type. More details are in

353 Table S1.

354 Duet initiation and answering analysis. If we assume that every spontaneous song

355 phrase produced by a male or female has been answered by its mate, we may consider that our

356 results reflect individual decisions (Logue \& Krupp, 2016). In total, the study species tend to

357 sing more in solos than duets. The three male phrase types remained unanswered by the female

358 in $60.8-79.4 \%$ of cases (Table S1). The very common female phrase Chock-series remained

359 unanswered by a mate in $81.9 \%$ of cases (Table S1). The female phrase types Kee-roo and

360 Chock remained unanswered in $37.0 \%$ and $53.8 \%$ of cases, respectively. A completely different

361 pattern was found for Keck calls as they were almost never answered (99.8\%) by males. The

362 Rasp calls were also rarely answered by males (76.0\%), but they were also very rarely recorded.

363 We speculate that both Kecks and Rasps are not produced by females to form duets, but just

364 when females are alarming (Kecks) or are highly excited (Rasps), males may also produce song

365 phrases, but not in a coordinated way with the female (Table S1). 
with surprisingly similar average rates (Table 1) which did not differ significantly between

368 phrase types (GLMM, $\beta \pm \mathrm{SE}=0.02 \pm 0.795, z=0.03, p=0.976)$. On the other hand, the

369 differences in the number of phrases within a bout (GLMM, $\beta \pm \mathrm{SE}=0.07 \pm 0.012, z=5.92, p<$

$3700.001)$ and as a consequence the bout duration (GLMM, $\beta \pm \mathrm{SE}=0.05 \pm 0.015, z=3.62, p<$

3710.001 ) were significantly different between bouts produced with different phrase types (with the

372 following pattern High whee-oo $>$ Low whee-oo $>$ Hwee-hwee). Thus, males produced solos

373 with a very regular and fixed rate, but obviously changed bout duration by producing more or

374 fewer phrases in a series. We did not record male solo bouts with more than a single phrase type.

375 A different situation was found for females (Table 1). As was mentioned already, three

376 types of vocalisations (Chock-series, Chocks and Kee-roos) were used by females as songs,

377 while the remaining two were used as calls (Kecks and Rasp). In the majority of cases the

378 Chock-series remained unanswered by males and they were never repeated one after another.

379 Chocks and Kee-roos produced as a solo had similar temporal organisation, typically with 4-8

380 notes in a bout (Table 1) and they were used both to initiate duets and as a response to males

381 during duets. Female solo song bouts of different types (Chock-series, Chocks and Kee-roos)

382 significantly differed in number of phrases (GLMM, $\beta \pm \mathrm{SE}=1.04 \pm 0.204, z=5.07, p<0.001)$,

383 duration $(\mathrm{GLMM}, \beta \pm \mathrm{SE}=2.81 \pm 0.192, z=14.63, p<0.001)$ and call rate $(\mathrm{GLMM}, \beta \pm \mathrm{SE}=-$

$38476.21 \pm 3.901, z=-19.53, p<0.001)$. Keck calls were clearly different from other vocalisations,

385 as they were produced with extremely high rates and sometimes in a very long series (Table 1).

386 Rasps were recorded rarely, hence it is hard to temporally characterise them in more detail.

387 However, recorded examples indicate a sudden and irregular appearance (Table 1). 
$393 \pm \mathrm{SE}=-3.57 \pm 1.721, z=-2.07, p=0.038)$ and had a lower rate $(62.5 \mathrm{vs} 94.6 \mathrm{phrases} / \mathrm{min}$

394 GLMM, $\beta \pm \mathrm{SE}=-29.22 \pm 3.229, z=-9.05, p<0.001)$ than female initiated duets. duets initiated by male and female (GLMM, $\beta \pm \mathrm{SE}=-1.75 \pm 0.114, z=-15.41, p<0.001)$. If duets were initiated by males, the number of male and female phrases within a duet was almost equal (Sex bias $=0.98 \pm 0.014,95 \% \mathrm{CI}: 0.95-1.01)$. However, if females were initiating duets, they produced significantly more phrases than males (Sex bias $=2.67 \pm 0.206,95 \% \mathrm{CI}: 2.27$ 3.08). Characteristically, males responded to females initiating duets with any type of their song phrase repertoire (Table S1). If a female initiated the duet with a Chock-series she always switched later in a bout to Chock or Kee-roo phrases (e.g. Fig. 4b, Table S1). Consequently,

Chock-series were never used within a duet and never repeated one after another.

405 Boubous started to vocalise on average $16 \pm 6.1 \mathrm{mins}$ before sunrise (95\%CI 30.0-3.3 mins 406 before sunrise; extremes from 61.1 mins before to 23.7 mins after sunrise) and that singing 407 activity was the highest during the first two hours after sunrise (Figs. 6-7). Interestingly, birds 408 were vocally active during the whole day, even between 11:00 and 15:00 when the temperature 409 was usually quite high $\left(24.8-31.0^{\circ} \mathrm{C}\right)$ in comparison to dawn $\left(14.5-16.4^{\circ} \mathrm{C}\right.$; more details in 410 Szymański et al. under review). Characteristically, the number of bouts per hour in which 
411 females were involved were small (Figs. 6-7), and we found no significant trends for number of

412 female solos produced during the daytime (GLMM, $\beta \pm \mathrm{SE}=0.07 \pm 0.047, z=1.54, p=0.124$ )

413 and duet bouts initiated by females (GLMM, $\beta \pm \mathrm{SE}=-0.02 \pm 0.019, z=-0.85, p=0.393$ ). Thus,

414 the main part of the overall variability of the singing activity during the day resulted from the

415 activity of male solos and duets initiated by males (Figs. 6-7). The number of male song bouts

416 significantly decreased during the day time (GLMM, $\beta \pm \mathrm{SE}=-0.32 \pm 0.107, z=-2.95, p=$

417 0.003), although male initiated duets did not differ significantly throughout the day (GLMM, $\beta \pm$

$418 \mathrm{SE}=-0.10 \pm 0.057, z=-1.78, p=0.075)$.

419 We analysed who, and with what call type, first started vocalising in the morning. When

420 we analysed 18 focal pairs, $78 \%$ of cases started with a male solo bout (and 9 of these 14 cases

421 were males calling with the Hwee-hwee phrase type). Duets were observed as the first call bout

422 in two pairs (11\%; Kee-roo — Low whee-oo and High whee-oo — Kee-roo) as were female

423 solos (two cases, 11\% of Kecks). A long series of Kecks given by females were observed

424 (personal observations) as an apparent response to a threat (human or squirrels close to nest) and

425 so these two early cases of Kecks given by females might be interpreted as an unspontaneous

426 dawn chorus but are more likely used as a response to a predator.

427

428 Discussion

429 Here we provide the first paper to thoroughly explore the form and potential functions of the

430 vocalisations, both in solo and duet form, of the Yellow-breasted Boubou. Through the use of a

431 microphone array setup we have been able to analyse natural singing and calling behaviours of

432 this species which provides basic information about the study species' vocalisations and can later

433 be used to better interpret experimentally induced behaviours. 
435 Boubou has a small and sex specific repertoire of vocalisations that are usually used in both a

436

437

438

439

440

441

442

443

444

445

446

447

448

449

450

451

452

453

454

455

456

solo and duet context. The males perform three distinct, tonal song phrases whilst the females

vocalise with five atonal, harsh notes (Figs. 2-3). All three male song types were produced with a

very repeatable pattern characterised by virtually fixed repetition rate both between phrase types

and between males. Moreover, series of tonal songs produced by males were similar in solos and duets.

For females we recorded five types of sexually specific, atonal vocalisations, but only

three of them seem to be functional song units (Chock-series, Chocks and Kee-roos). They were

produced as solos or in duets, and when they were performed together with male vocalisations

they were coordinated with the male output (Fig. 5). The common Keck call was given by

females almost exclusively as a solo. Based on our visual observations this is an alarm call

produced in the context of the potential presence of a predator, e.g. squirrel close to the nest or a

human. The Rasp calls were recorded extremely rarely and if they appeared alongside a male call

(14 bouts only) they were not synchronized precisely in time. Again, visual observations of such

displays were found in most of the cases during playback experiments and suggest that Rasp is a

high excitation call (A Wheldon et al., 2020, unpublished data testing response of focal pairs to

different types of song). For example, they were recorded during a failed experiment where two

adjacent pairs approached the speakers and met and chased each other aggressively (personal

observation). To summarise, within the studied population males and females used sexually

dimorphic vocalisations, both in the context of solo and duet singing.

Duets. The rules of duet organisation for the Yellow-breasted Boubou seem to be simple:

(1) both sexes may start a duet but males do so much more frequently than females; (2) males

Peer] reviewing PDF | (2020:06:50332:1:2:NEW 14 Aug 2020) 
457 always produce their phrases with a very regular time pattern while females add one or more

458 phrases (Chock or Kee-roo) per single male call; (3) males and females initiated duets with any

459 kind of their sex specific song phrases, but female Chock-series were never produced inside

460 duets; (4) the majority of duets consist of one male and one female phrase type only; (5) females

461 produce more phrases per male phrase if they started the duetting bout. So, the duets of the study

462 species are sex specific, and male and female components are easy to identify even from a longer

463 distance. As summarised in Hall's (2004) review, loud, locatable and sex-specific duet elements

464 support the hypothesis for maintaining contact. Indeed, in the Yellow-breasted Boubou the

465 environment is visually occluded and the duet could be initiated in order to locate a partner. On

466 the other hand, they also produce duets when sitting right next to each other and so the

467 maintaining contact hypothesis is not the only function (Hall, 2004). The aforementioned duet

468 properties are also described as being linked to guarding/preventing partner usurpation as well as

469 for joint resource defence (Hall, 2004) and it seems Yellow-breasted Boubous also duet to

470 convey information about their mated status and defence ability. Further research on this topic

471 demands more detailed information about the duet characteristics in relation to duet context and

472 the status of each bird.

473 When assessing duet function, it is important to look at the different sexes. Yellow-

474 breasted Boubous have a sex specific repertoire used for both solo and duet bouts Within the

475 Laniarius genus, the situation of sex specific call types is complicated. For example, in some

476 species like the Gabela Bush-shrike (Laniarius amboimensis) and Red-naped Bush-shrike

477 (Laniarius ruficeps), males and females produce structurally similar phrases (Fry, 2020b; c).

478 However, the Tropical Boubou has strictly sex specific phrases when performing duets (Grafe \&

479 Bitz, 2004a), with males using tonal whistles and females producing both (sex specific) tonal 
480 whistles and atonal notes. Another interesting bush-shrike is the Southern Boubou (Laniarius

481 ferrugineus) in which males and females exchange phrase types when producing duets (Wickler

$482 \&$ Seibt, 1982). With the absence of plumage or size dimorphism in certain duetting species, the

483 ability to produce sex specific song types is one way that duet members can establish mate

484 guarding or paternity guarding behaviours through sex recognition (Hall, 2004). Both the

485 Tropical Boubou and Crimson-breasted Shrike (Laniarius atrococcineus) are Malaconotidae

486 species that utilise sex specific songs for mate guarding behaviours (Grafe \& Bitz 2004a; van

487 den Heuvel, Cherry \& Klump, 2014), and so it is likely that the role of sex specific songs in the

488 Yellow-breasted Boubou is a function of mate guarding behaviour in this monomorphic species.

489 If we compare all Laniarius species for which we have any data on vocal behaviour (Winkler,

490 Billerman \& Lovette, 2020), it seems that in the majority of cases males tend to produce whistle

491 like phrases while females use (at least more often) atonal harsh notes. Such differences may

492 suggest some functions which remain to be studied in detail. Tonal whistles are more efficiently

493 propagated through dense forest habitat (Boncoraglio \& Saino, 2007) which, together with a

494 higher amplitude, suggests that male phrases (A Wheeldon et al., 2020 unpublished data) are

495 aimed at receivers at a further distance than the phrases produced by females. Although males

496 share all phrase types they are clearly individually distinct (Linhart et al., 2019). At the moment

497 we do not know if this is also the case for females due to the complexity of the atonal harsh notes

498 and limited amount of isolated female recordings in the field. However, experiments suggest that

499 females can discriminate easily between their own mate and stranger males based on songs while

500 there is no evidence that it works the other way around (own unpublished data). Such

501 observations support the idea that differentiated structures of male and female song only reflect

502 their functional distinctiveness. 
another aspect of duetting behaviour necessary to understand its function. In this study we

collected material representing a pairs' activity for an entire daily activity period during the peak

of the breeding season. The analysed material was collected during eight different days between

12 Nov and $5 \mathrm{Dec}$, and for 18 pairs, hence it is rather unlikely that it is biased because of, for

example, unusual weather or random events (e.g. losing brood). In general, the Yellow-breasted

511 Boubou has a classic diurnal pattern of vocal activity, with a clear peak early in the morning and

512 smaller peak in activity before dusk. Hence, this pattern was similar to that of other duetting

513 species (e.g. White-eared Ground sparrow Melozone leucotis, Sandoval et al. 2016). Several

514 more detailed observations may help in linking their solos and duets with particular functions.

515 For example, Yellow-breasted Boubous do not exhibit any regular diel variation in any of the

516 duet types used and peaks of diurnal activities were largely caused by male solos or any duets

517 initiated by males. Similarly, the Tropical Boubou which produces up to 12 duet types did not

518 exhibit any consistent variation of how these types are used during the day (Grafe \& Bitz,

519 2004a)..

$520 \quad$ For the Yellow-breasted Boubou, differences in durations of male and female

521 unanswered solos suggest that males are regularly producing long bouts of solos, which are often

522 responded to by neighbouring males (or pairs), whilst females are just trying to evoke a male

523 response and stop calling shortly after if there is no response. Thus, we observed some kind of

524 dichotomy of vocal activity for males and females. The only female vocalisation type to show

525 any diel variation was the Keck call which is produced more often at the end of the day and with 
526 a high calling rate. It seems that this call type is linked to an alarm context as it was often

527 produced when human observers were close, and usually followed by the males' appearance

528 (personal observations). Langmore (1998) explains that certain female call types may be used to

529 coordinate the care of young, and so it may be that such vocalisations are produced by the

530 females of the study species in order to synchronise certain behaviours with their mate.

531 Therefore, we do not rule out that this alarm call can also be used to summon the mate.

532 Females of the study species vocalise less than males in both solo and their initiated

533 duets. The amount in which females sing in the tropics varies across species. Chirruping

534 Wedgebill (Psophodes cristatus) females vocalise at a lower rate than males (Austin et al.,

535 2019), this reduced rate of vocalising could be because females may only increase the amount of

536 singing if a mate dies and so they need to be able to hold a territory independently (Langmore,

537 1998). Conversely, in certain species the females have an increased singing activity compared to

538 males. Slate-coloured Boubou (Laniarius funebris) females have a higher vocal activity due to

539 aggressive encounters (Wickler \& Seibt, 1979). In general, it seems that females singing more

540 intensively than males are relatively rare. Dutour \& Ridley (2020) indicated only six such

541 species in literature, and some of them concern duetting birds, for example the Cocos Flycatcher

542 (Nesotriccus ridgwayi) (Kroodsma et al., 1987) and New Zealand Bellbird (Anthornis melanura)

543 (Bruntin \& Li, 2006; Brunton et al., 2008). A reason for the variability in male and female

544 vocalisation rates may be due to the hormonal balance in a species, with higher testosterone

545 levels equating to increased vocal activity (Odom et al., 2014). It appears the Yellow-breasted

546 Boubou males are more vocally active than females as there is less need for aggressive solo

547 displays by females and possibly a lack in intense female-female competition due to the

548 monogamous life history strategy pursued. However, this interpretation must be treated with 
549 caution, as it is known that in some closely related species, despite social monogamy the

550 proportion of extra pair offspring could be substantial (van den Heuvel et al., 2014).

551 The dawn chorus acts as a communication network, whether signals are directed at an

552 individual or are eavesdropped by other individuals (Burt \& Vehrencamp, 2005). In the Yellow-

553 breasted Boubou, the first calls at dawn are typically produced by males as solo calls, followed

554 by female solos and duets. Surprisingly, the least frequently produced male phrase type, the

555 Hwee-hwee, was usually used as the first vocalisation type in the morning. In Banded Wrens

556 (Thryophilus pleurostictus), vocalisations that are produced in the dawn chorus are usually

557 longer and have a higher bandwidth than other songs in their repertoire (Trillo \& Vehrencamp,

558 2005). However, the Hwee-hwee phrase is not used exclusively as an early morning song and is

559 not so structurally different from other male whistles. Yellow-breasted Boubou pairs hold stable,

560 year-round territories and so it seems that the morning peak in male vocal activity followed by

561 the females joining mates in duets might have a double function. It could be interpreted as

562 something like checking the attendance list, which could be important for both within-pair as

563 well as between-neighbour communication. Similarly in White-eared Ground-sparrows, solos are

564 produced as the first vocalisation type as a way of demonstrating pair bond maintenance

565 (Sandoval et al., 2016) however, it may also be a way of eliciting extra-pair copulations. Black-

566 capped Chickadee (Poecile atricapillus) females can compare the solo songs sung by males in

567 the morning and use this to assess fitness (Gammon, 2004). Yellow-breasted Boubou pairs are

568 described as utilising a monogamous breeding system (Harris \& Franklin, 2010) and so it is

569 likely that the first solos calls produced are a means of pair-bond maintenance or territorial

570 defence, rather than to seek extra-pair paternity opportunities.

571

572 Conclusions 
573 Yellow-breasted Boubous represent a duetting species in which males are more vocally active

574 than females and duetting is not a dominating type of vocal activity. Males and females have

575 distinctive, small and sex specific repertoires used both in solos and duets. There is a dawn

576 chorus effect shown with male solos that can be interpreted as a form of within and between pair

577 communication. We found some interesting differences in call types used for both males and

578 females, suggesting that some calls may have specific functions. Our findings suggest that male

579 solos and duets initiated by males are used for territorial defence. On the other hand, the female

580 calling pattern with more effort being put into female-initiated duets suggests that their own calls

581 are directed to own mates.

582

583 Acknowledgements

584 We thank Ernest Vunan Amohlon for his help in organising field work in Cameroon and all

585 Kedjom-Keku People Community for allowing to study birds on their land, and dr Moses Njoya

586 from Bamenda University for help in organising local permits.

\section{References}

591 Austin VI, Higgott C, Viguier A, Grundy L, Russell AF, Griffith SC. 2019. Song rate and

592 duetting in Chirruping wedgebill (Psophodes cristatus): Frequency form and functions. Emu 593 119:138-146.

594 Boncoraglio G, Saino N. 2007. Habitat structure and the evolution of bird song: A meta-analysis

595 of the evidence for the acoustic adaptation hypothesis. Functional Ecology 21:134-142.

596 Borrow N, Demey R. 2001. Birds of Western Africa. London (UK): Christopher Helm. 
597 Brown RN, Lemon RE. 1979. Structure and evolution of song form in the wrens Thyothorus 598 sinaloa and T. felix. Behavioral Ecology and Sociobiology 5:111-131.

599 Brunton DH, Li X. 2006. The song structure and seasonal patterns of vocal behaviour of male 600 and female bellbirds (Anthornis melanura). Journal of Ethology 24:17-25.

601 Brunton DH, Evans B, Cope T, Ji W. 2008. A test of the dear enemy hypothesis in female New 602 Zealand bellbirds (Anthornis melanura): female neighbours as threats. Behavioral Ecology 603 19:791-798.

604 Budka M, Czyż M, Skierczyńska A, Skierczyński M, Osiejuk TS. 2020. Duration of survey 605 changes interpretation of habitat preferences: An example of an endemic tropical songbird, the 606 Bangwa Forest Warbler. Ostrich 91, DOI: 10.2989/00306525.2020.1723139.

607 Burt JM, Vehrencamp SL. 2005. Dawn chorus as an interactive communication network. In: 608 McGregor PK ed. Animal communication networks. Cambridge: Cambridge University Press, $609320-343$.

610 Catchpole CK, Slater PJB. 2008. Bird Song: Biological themes and variations. 2nd ed.

611 Cambridge: Cambridge University Press.

612 Dahlin CR, Benedict L. 2014. Angry birds need not reply: A perspective of the flexible form and 613 multifunctionality of avian vocal duets. Ethology 120:1-10. DOI 10.1111/eth.12182

614 Dilger WC. 1953. Duetting in the crimson-breasted barbet. Condor 55:220-221.

615 Dutour M, Ridley AR. 2020. Females sing more often and at higher frequencies than males in 616 Australian magpies. Behavioural Processes 172:104045.

617 Fry H. 2020a. Yellow-breasted Boubou (Laniarius atroflavus), version 1.0. In: del Hoyo J., 618 Elliott A, Sargatal J, Christie DA, de Juana E., eds. Birds of the World. Ithaca, NY, USA: Cornell 
619 Lab of Ornithology. Available at https://doi.org/10.2173/bow.yebbou1.01 (accessed 24 June 620 2020).

621 Fry H. 2020b. Gabela Bush-shrike (Laniarius amboimensis), version 1.0. In: del Hoyo J., Elliott 622 A, Sargatal J, Christie DA, de Juana E., eds. Birds of the World. Ithaca, NY, USA: Cornell Lab 623 of Ornithology. Available at https://doi.org/10.2173/bow.gabbus1.01 (accessed 24 June 2020).

624 Fry H. 2020c. Red-naped Bush-shrike (Laniarius ruficeps version 1.0. In: del Hoyo J., Elliott A, 625 Sargatal J, Christie DA, de Juana E., eds. Birds of the World. Ithaca, NY, USA: Cornell Lab of 626 Ornithology. Available at https://doi.org/10.2173/bow.renbus1.01 (accessed 24 June 2020). 627 Fry H, Bonan A. 2020. Bush-shrikes (Malaconotidae). In: del Hoyo J., Elliott A, Sargatal J, 628 Christie DA, de Juana E., eds. Handbook of the Birds of the World Alive. Barcelona: Lynx 629 Edicions. Available at https://www.hbw.com/node/52357 (accessed 17 April 2020).

630 Gammon DE. 2004. Black-capped chickadee dawn chorus and subsequent sexual activity. 631 Wilson Bulletin 116:252-256.

632 Garamszegi LZ, Eens M, Erritzøe J, Møller AP. 2005. Sexually size dimorphic brains and song 633 complexity in passerine birds. Behavioral Ecology 16: 335-345.

634 Grafe TU, Bitz JH. 2004a. Functions of duetting in the tropical boubou, Laniarius aethiopicus:

635 Territorial defence and mutual mate guarding. Animal Behaviour 68:193-201.

636 Grafe TU, Bitz HJ, Wink M. 2004. Song repertoire and duetting behaviour of the tropical 637 boubou, Laniarius aethiopicus. Animal Behaviour 68:181-191.

638 Greenwood JJD. 2001. Birds, Biodiversity of. In: Levin, S. ed. Encyclopedia of Biodiversity:

639 Second Edition. Academic Press, 600-625.

640 Hall ML. 2004. A review of hypotheses for the functions of avian duetting. Behavioral Ecology 641 and Sociobiology 55:415-430. 
642 Hall ML. 2009. A review of vocal duetting in birds. Advances in the Study of Behavior 40:67643121.

644 Harris T, Franklin K. 2010. Helm Identification Guides: Shrikes and Bush-shrikes. Londond: 645 A\&C Black Publishers Ltd.

646 Hooker T, Hooker BI. 1969. Duetting. In: Hinde RA. ed. Bird vocalisations. London: Cambridge 647 University Press, 85-205.

648 Kahn ZA, Moser-Purdy C, Mennill DJ. 2018. Sing and do not stray: male rufous-and-white 649 wrens use duets and physical behaviours to guard their mates. Animal Behaviour 143:35-42. 650 Koloff J, Mennill DJ. 2013. The responses of duetting antbirds to stereo duet playback provide 651 support for the joint territory defence hypothesis. Ethology 119:462-471.

652 Kroodsma DE, Ingalls VA, Sherry TW, Werner TK. 1987. Songs of the Cocos flycatcher: vocal 653 behaviour of a suboscine on an isolated oceanic island. Condor 89:75-84.

654 Lamprecht J, Kaiser A, Terers A, Kirchgessner C. 1985. Distance call duets in bar-headed geese 655 (Anser indicus): co-operation through visual relief of the partner? Zeitschrift für Tierpsychologie $65670: 211-218$.

657 Langmore NE. 1998. Functions of duet and solo songs of female birds. Trends in Ecology and 658 Evolution 13:136-140.

659 Langmore NE. 2002. Vocal duetting: Definitions, discoveries and directions. Trends in Ecology 660 and Evolution 17:451-452.

661 Linhart P, Osiejuk TS, Budka M, Šálek M, Špinka M, Policht R, Syrová M, Blumstein DT. 2019.

662 Measuring individual identity information in animal signals: overview and performance of 663 available identity metrics. Methods in Ecology and Evolution 10:1558-1570. 
664 Logue DM. 2005. Cooperative defence in duet singing birds. Cognition, Brain, Behavior 9:497665510.

666 Logue DM, Hall ML. 2014. Migration and the evolution of duetting in songbirds. Proceedings of 667 the Royal Society B Biological Sciences 281:20140103.

668 Logue DM, Krupp DB. 2016. Duetting as a collective behavior. Frontiers in Ecology and 669 Evolution 4:7. DOI: 10.3389/fevo.2016.00007

670 Mennill DJ, Vehrencamp SL. 2008. Context-dependent functions of avian duets revealed by 671 microphone-array recordings and multi-speaker playback. Current Biology 18:1314-1319.

672 Odom KJ, Hall ML, Riebel K, Omland KE, Langmore NE. 2014. Female song is widespread and 673 ancestral in songbirds. Nature Communication 5:3379.

674 Odom KJ, Omland KE, Price J. 2015. Differentiating the evolution of female song and male675 female duets in the new world blackbirds: Can tropical natural history traits explain duet 676 evolution? Evolution 69:839-847.

677 Odom KJ, Logue DM, Studds CE, Monroe MK, Campbell SK, Omland KE. 2017. Duetting 678 behaviour varies with sex, season, and singing role in a tropical oriole (Icterus icterus).

679 Behavioral Ecology 28:1256-1265.

680 Olszowiak KK. 2018. Zmienność sezonowa aktywności głosowej dzierzyka żółtobrzuchego 681 Laniarius atroflavus (Shelley, 1887) [Seasonal pattern of vocal activity in the Yellow-breasted 682 Boubou (Laniarius atroflavus) (Shelley 1887)]. MSc thesis. Adam Mickiewicz University, 683 Poznań, Poland.

684 Orme D, Davies RG, Burgess M, Eigenbrod F, Olson VA, Webster AJ, Tzung-Su D, Rasmussen 685 PC, Ridgley RS, Stattersfield AJ, Bennet PM, Blackburn TM, Gaston KJ, Owens IPF. 2005. 
686 Global hotspots of species richness are not congruent with endemism or threat. Nature 438:10166871019.

688 Osinubi ST, McGraw KJ, Ottosson U, Brown JA, Briskie JV, Chapman HM. 2018. Carotenoid689 based plumage pigmentation and concentration as a function of sex and habitat type in the 690 Yellow-breasted Boubou Laniarius atroflavus. Ostrich 89:259-264.

691 Price JJ. 2015. Rethinking our assumptions about the evolution of bird song and other sexually 692 dimorphic signals. Frontiers in Ecology and Evolution 3:40. DOI: 10.3389/fevo.2015.00040 693 Reif J, Hořák D, Sedláček O, Riegert J, Pešata M, Hrázský Z, Janeček S, Storch D. 2006. 694 Unusual abundance-range size relationship in an Afromontane bird community: the effect of 695 geographical isolation? Journal of Biogeography 33:1959-1968.

696 Riebel K, Odom KJ, Langmore NE, Hall ML. 2019. New insight from female bird song: towards 697 an integrated approach to studying male and female communication roles. Biology Letters $698 \quad$ 15:20190059.

699 Riegert J, Přibylová A, Sedláček O. 2004. Notes on calls of the Yellow-breasted Boubou 700 (Laniarius atroflavus) during the breeding season in NW Cameroon. Biological Letters 41:181701184.

702 Sandoval L, Mendez C, Mennill DJ. 2016. Vocal behaviour of White-eared ground sparrows 703 (Melozone leucotis) during the breeding season: Repertoires, diel variation, behavioural contexts, 704 and individual distinctiveness. Journal of Ornithology 157:1-12.

705 Seddon N, Tobias JA. 2009. Signal jamming mediates sexual conflict in a duetting bird. Current 706 Biology 19:577-582.

707 Sedláček O, Reif J, Hořák D, Riegert J, Pešata M, Klvana P. 2007. The birds of a montane forest 708 mosaic in Big Babanki area, Bamenda Highlands, Cameroon. Malimbus 29:89-100. 
709 Seibt U, Wickler, W. 1977. Duettieren als Revier-Anzeige bei Vogeln. Zeitschrift für

710 Tierpsychologie 43:180-187.

711 Serle W. 1981. The breeding seasons of birds in the lowland forest and in montane forest of

712 West Cameroon. Ibis 123:62-74.

713 Sonnenschein E, Reyer H. 1984. Biology of the slate-coloured boubou and other bush shrikes.

714 Ostrich 55: 86-96.

715 Stuart SN. ed. 1986. Conservation of Cameroon montane forests. Cambridge: International

716 Council for Bird Preservation.

717 Szymański P, Olszowiak KK, Wheeldon A, Budka M, Osiejuk TS. (in revision) Passive

718 acoustics monitoring gives a new insight into year-round duetting behaviour in a tropical

719 songbird. Ecological Indicators in revision

720 Trillo PA, Vehrencamp SL. 2005. Song types and their structural features are associated with

721 specific contexts in the banded wren. Animal Behaviour 70:921-935.

722 Topp SM, Mennill DJ. 2008. Seasonal variation in the duetting behaviour of rufous-and-white

723 wrens (Thryothorus rufalbus). Behavioral Ecology and Sociobiology 62:1107-1117.

724 Tye H. 1992. Reversal of breeding season by lowland birds at higher altitudes in western

725 Cameroon. Ibis 134:154-163.

726 van den Heuvel IM, Cherry MI, Klump GM. 2014. Crimson-breasted shrike females with extra

727 pair offspring contributed more to duets. Behavioral Ecology and Sociobiology 68:1245-1252.

728 Wickler W, Seibt U. 1979. Duetting: A daily routine of Laniarius funebris, the Slate-coloured

729 boubou (Aves: Laniidae). Zeitschrift für Tierpsychologie 51:153-157.

730 Wickler W, Seibt U. 1982. Song splitting in the evolution of duetting. Zeitschrift für

731 Tierpsychologie 59: 127-140. 
732 Winkler DW, Billerman SM, Lovette IJ. 2020. Bushshrikes and Allies (Malaconotidae), version

733 1.0. In: S. M. Billerman, SM, Keeney BK, Rodewald PG, Schulenberg TS., eds. Birds of the

734 World. Ithaca, NY, USA: Cornell Lab of Ornithology. Available at

735 https://doi.org/10.2173/bow.malaco2.01 (accessed 24 June 2020). 


\section{Figure 1}

Sketch illustration of multichannel recording output with different pairs of the Yellowbreasted Boubous producing alternating, overlapping and type matching song bouts.

For simplicity only three channels presented.

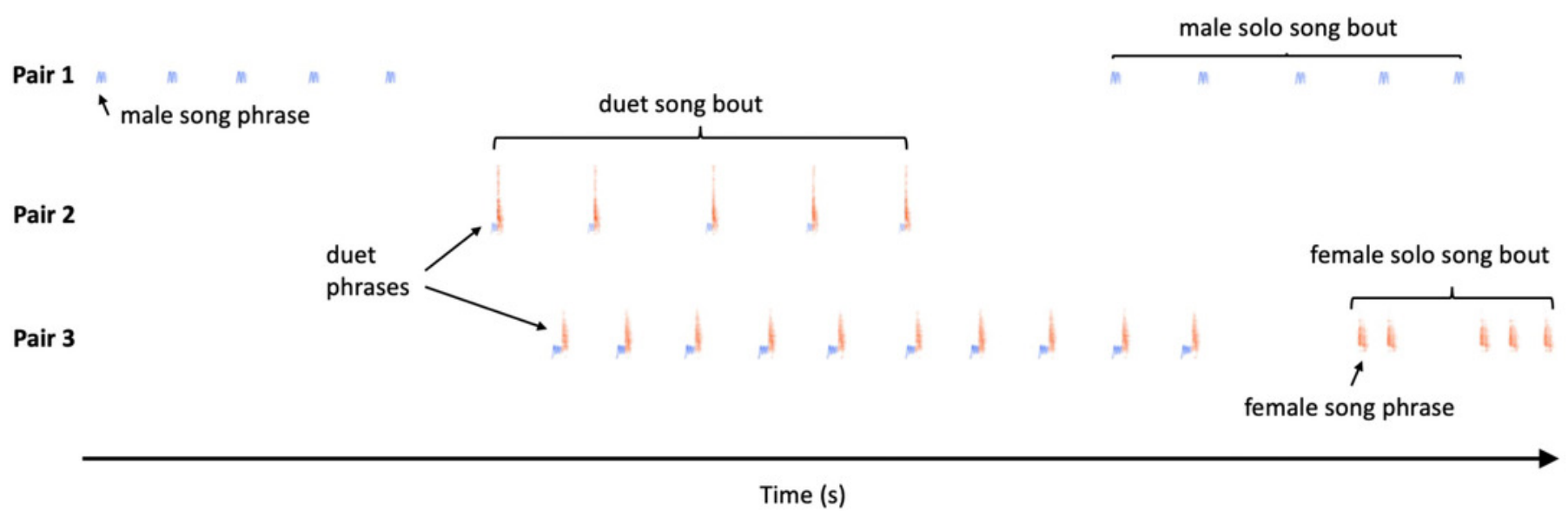




\section{Figure 2}

Illustration of individual variation male song phrases $(b, d, f)$, which enables individual recognition $(a, c, e)$.

The right panels present three examples of each song type derived from the repertoire of three males: (b) - High whee-oo, (d) - Low whee-oo, and (f) - Hwee-hwee. What is visible at first glance, despite sharing the same general pattern within a song phrase type, each individual has some specificity in the course of song whistles. These differences are easy to detect when Peak Frequency Contour measurement of Raven Pro is chosen with option Enable Measurement Plots on. Moreover, these small differences are individually invariable as illustrated on the left panels (a, c, e). Scatterplots illustrated with colour separation of male song phrases for several song phrases measured for three males. Variables pc1 and pc2 are the two first principal components derived from original time-frequency variables of song phrase variation measured in Raven Pro (Principal Component Analysis with Varimax rotation and Kaiser normalisation). The pc1 explained $48.9 \%$ of original song variation and had the stronger loadings on several frequency measures (like low and high frequency, delta frequency, Q1 and Q3 frequency and peak frequency); the pc2 explained 37.9\% of original variation and had the heaviest loading on time related measures (e.g. delta time, IQR Duration). 

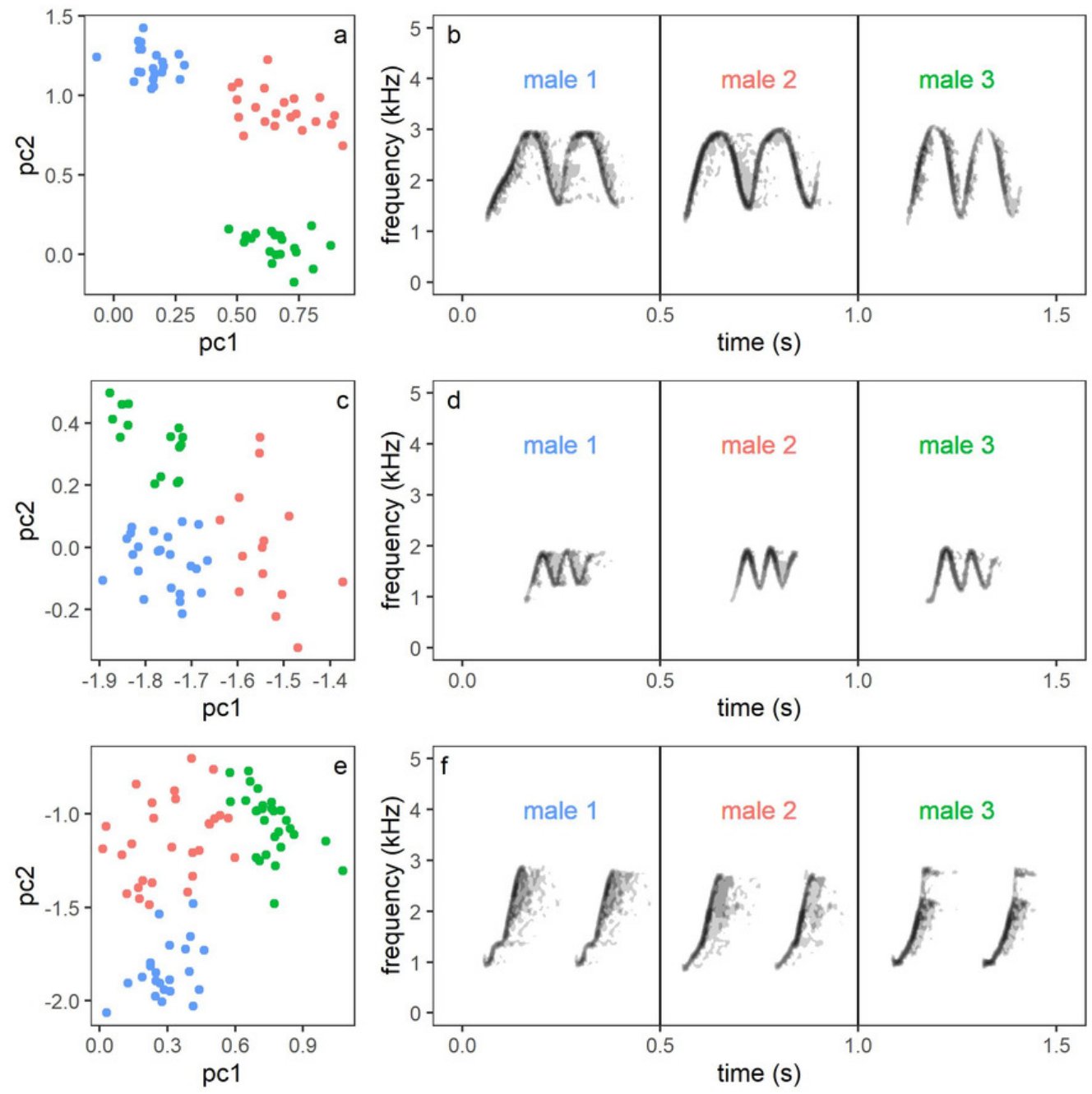
Figure 3

Examples of all three types of the Yellow-breasted Boubou male songs produced as solo.

(a) High whee-00, (b) Low whee-00, and (c) Hwee-hwee phrase types. Singing rate is typical for the species. The relevant sounds are included as supplement. 


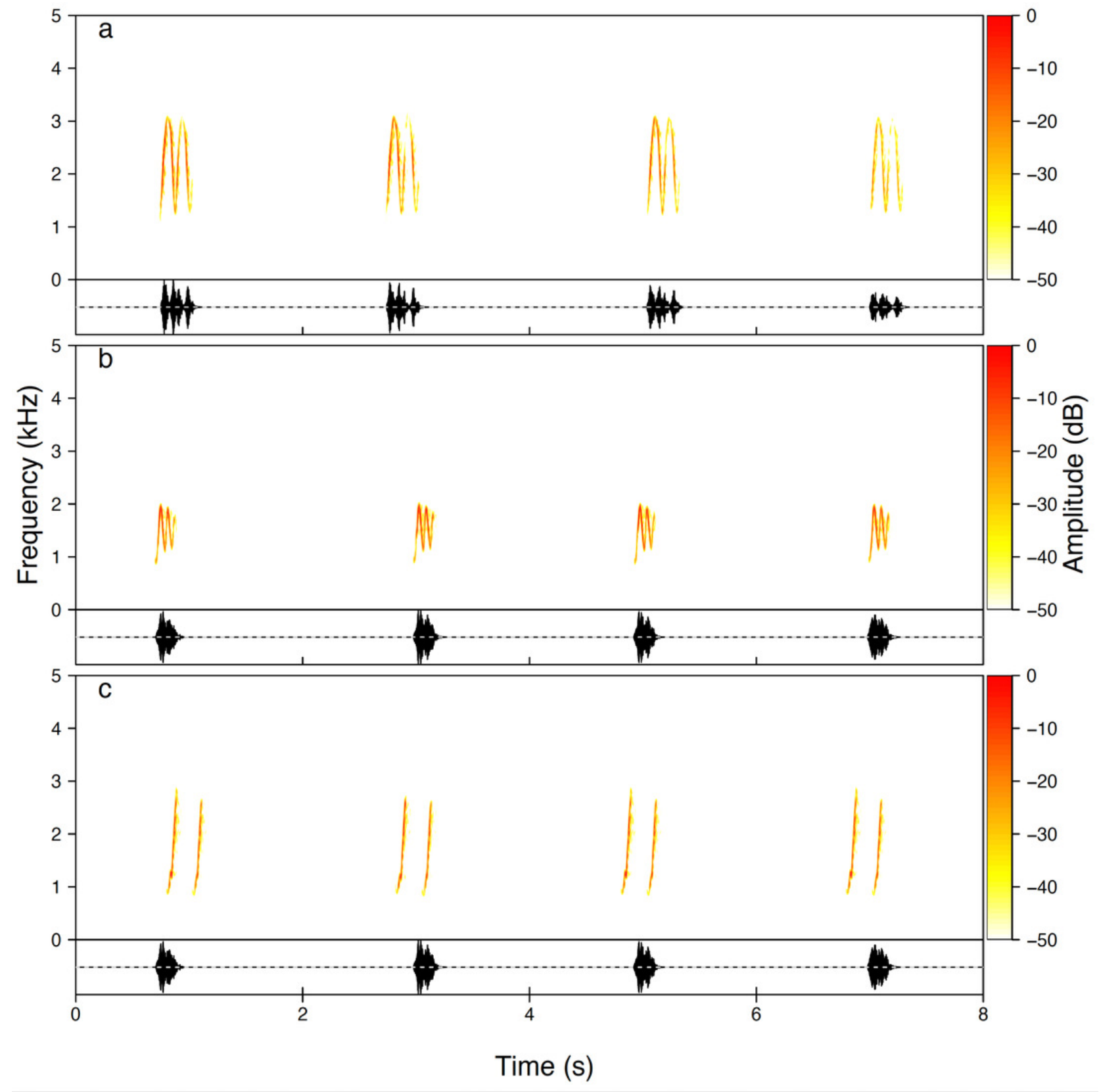


Figure 4

Examples of the Yellow-breasted Boubou female song phrase and call type repertoire.

(a-e) Chock-series phrases always produced in series, here from 2 to 7 , and used by females to initiate duets; (f) Kee-roo song phrase, (g) Keck - alarm call, (h) Rasp - excitation call, (im) Chock song phrases used in response to male and to lead duet. The relevant sounds are included as supplement.

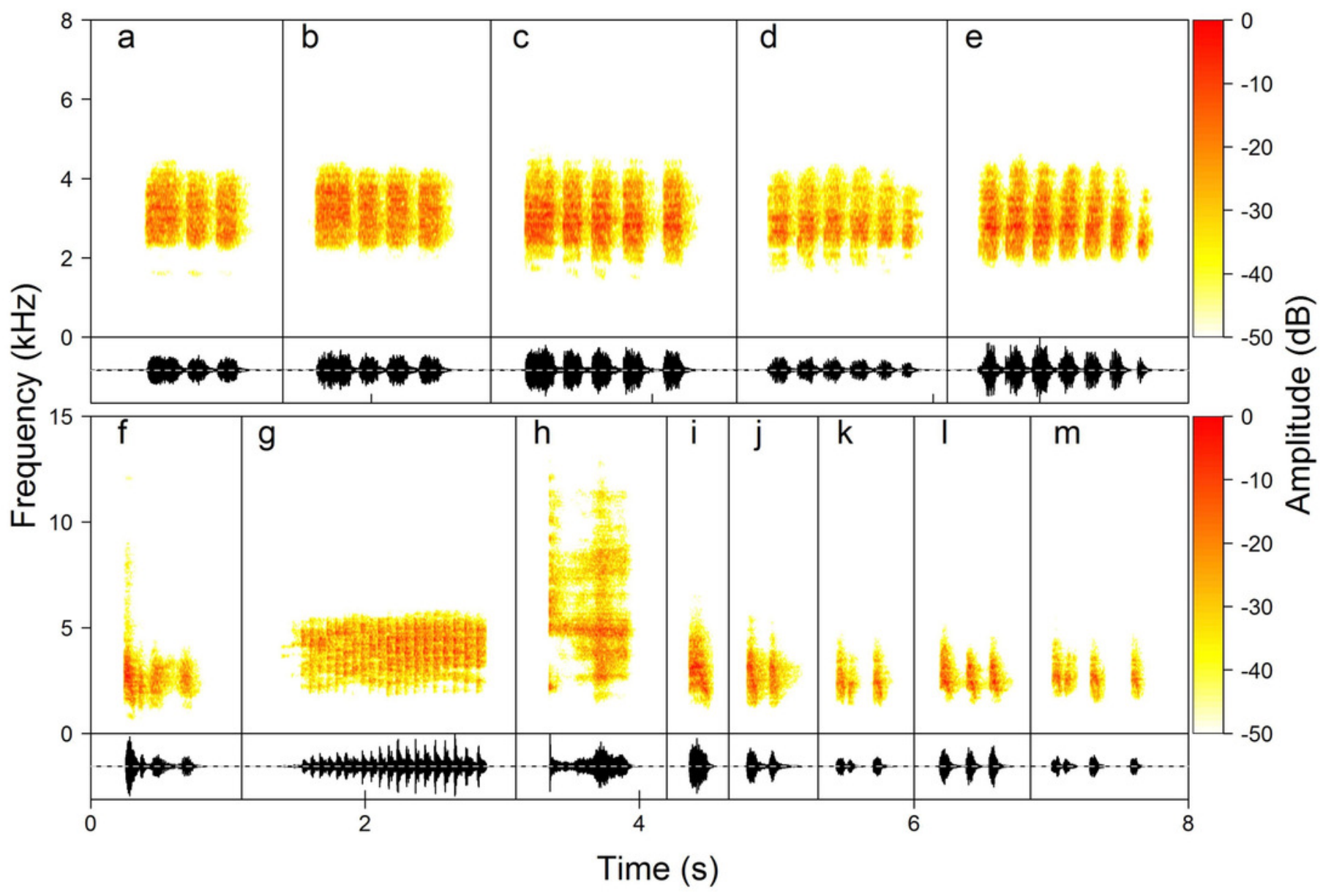


Figure 5

Examples of the Yellow-breasted Boubou duets.

(a) male-initiated and male-led duet - male High whee-oo and female Chock, (b) female-led duet - female Chocks and male Low whee-0o, and (c) female-initiated and female-led duet triple or double or female Chocks and male Hwee-hwee phrase types. Duetting rate is typical for the species. The relevant sounds are included as supplement.

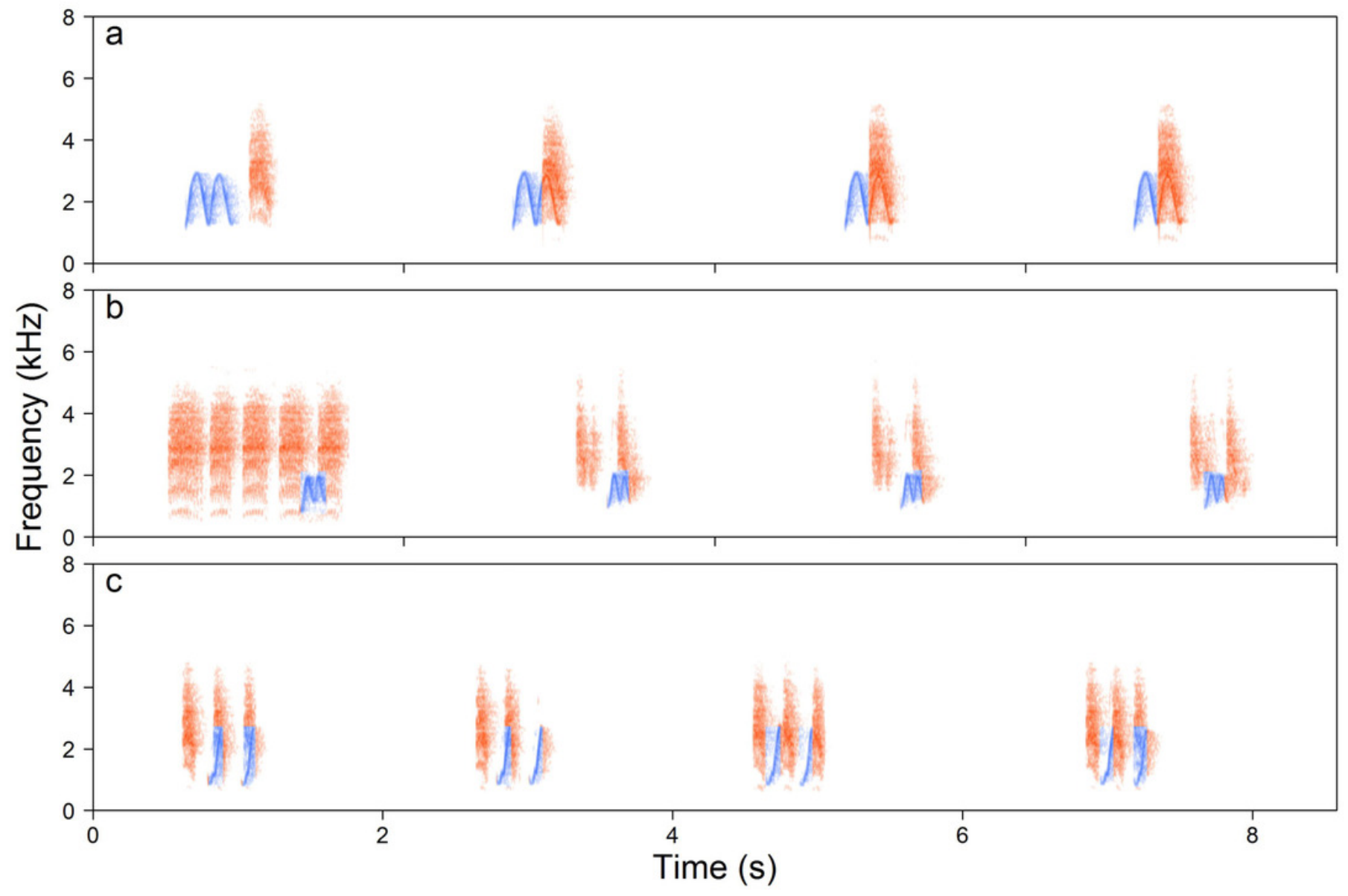


Figure 6

Number of solo song bouts of males and females per hour / per pair of the studied Yellow-breasted Boubou.

Boxes indicate median, 25th-75th percentile and lower-upper adjacent values. Only data for 18 focal pairs included.

a

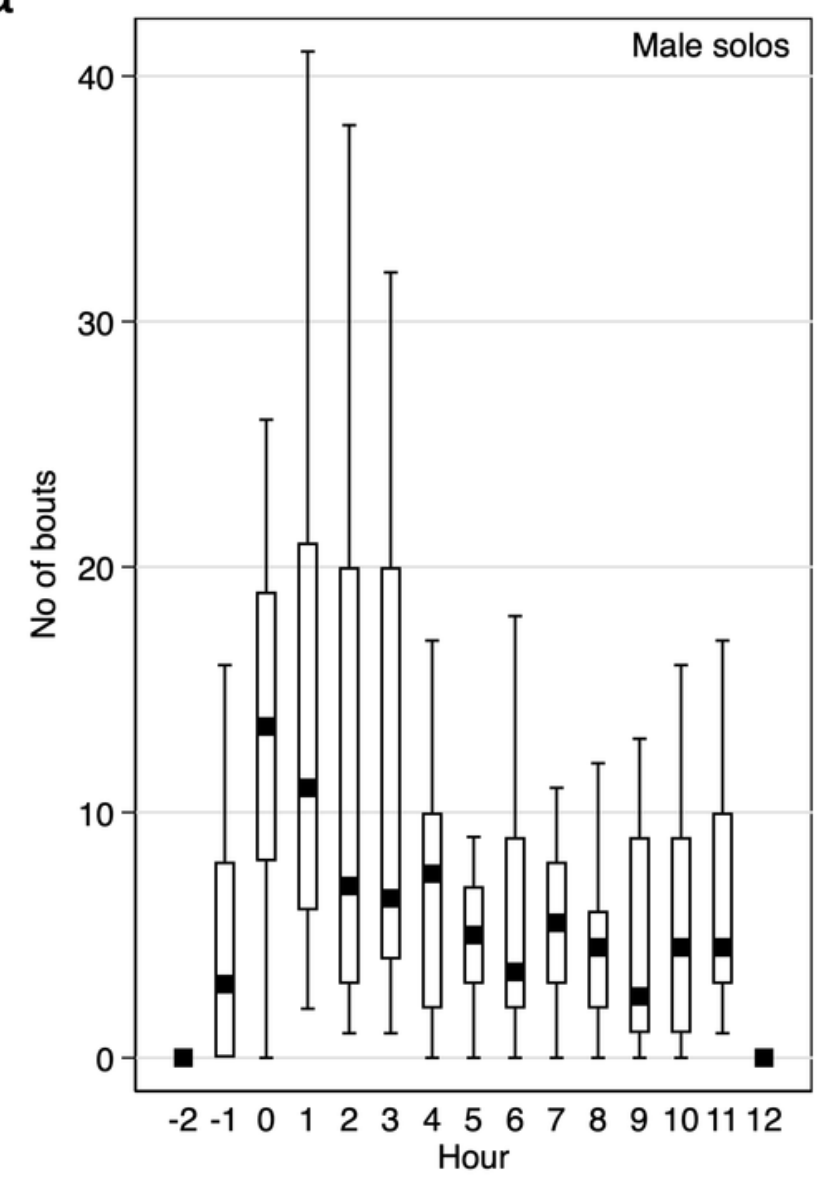

b

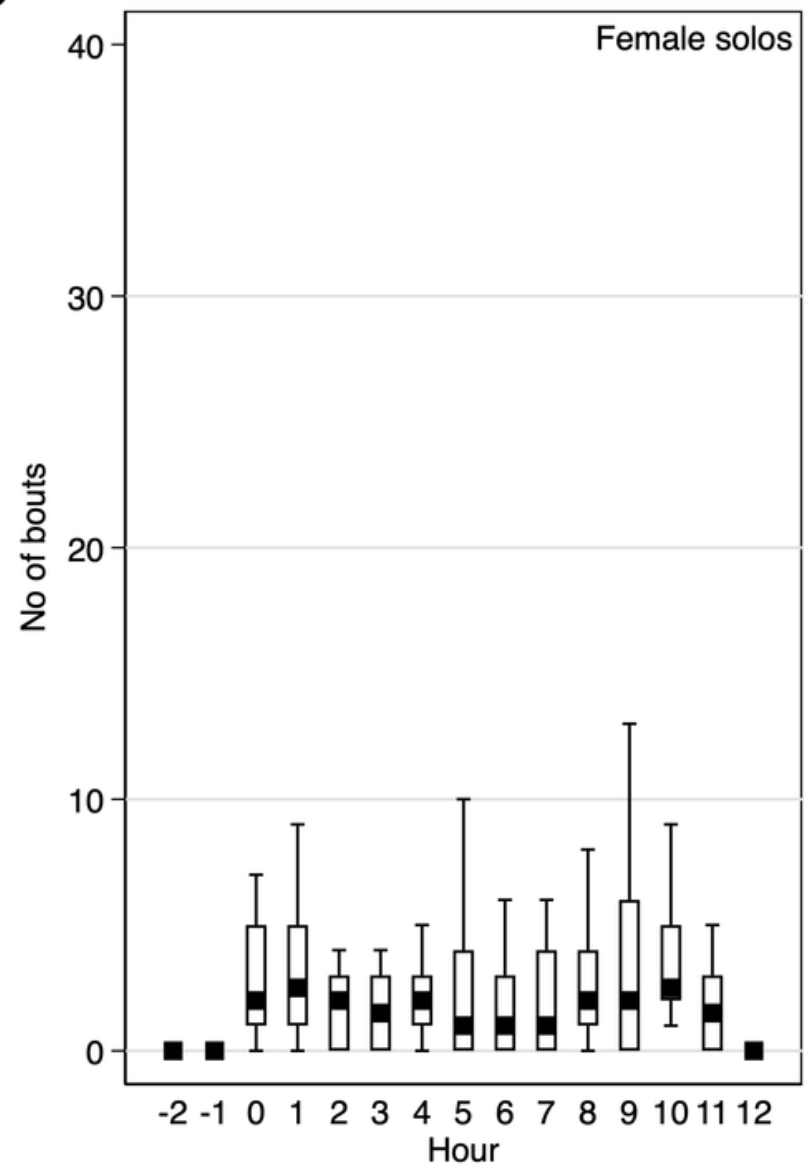


Figure 7

Number of male and female initiated duet bouts per hour / per pair of the studied Yellow-breasted Boubou.

Boxes indicate median, 25th-75th percentile and lower-upper adjacent values. Only data for 18 focal pairs included.

a

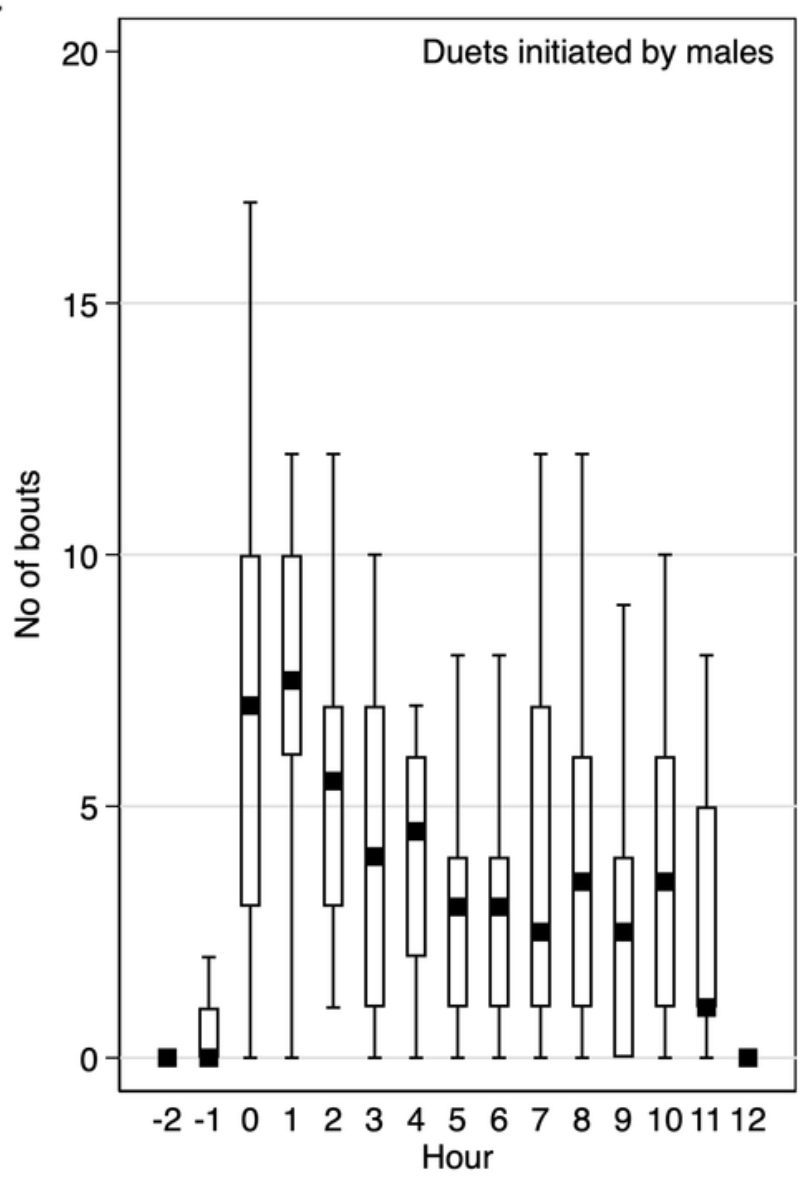

b

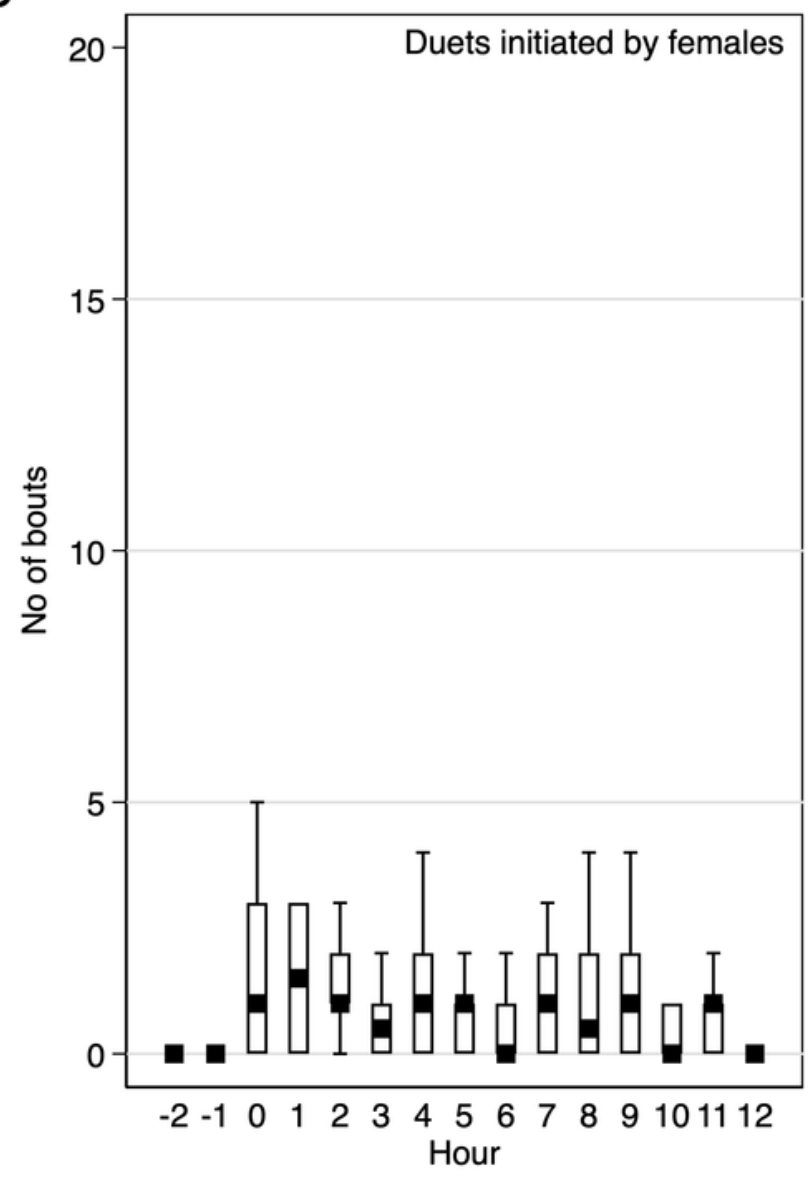




\section{Table $\mathbf{1}$ (on next page)}

Temporal characteristics of song phrases and call bouts of Yellow-breasted Boubou produced solo by males and females.

"Keck and Rasp vocalisations were recognised as functional calls (alarm and excitement). See text for details 
Table 1. Temporal characteristics of song phrases and call bouts of Yellow-breasted boubou produced solo by males and females.

2

\begin{tabular}{lcccccc}
\hline Vocalization & \multicolumn{2}{c}{ No of units in a bout } & \multicolumn{2}{c}{ Bout duration (s) } & \multicolumn{2}{c}{ Rate (units/min) } \\
& $\bar{x} \pm \mathrm{SE}$ & $95 \% \mathrm{CI}$ & $\bar{x} \pm \mathrm{SE}$ & $95 \% \mathrm{CI}$ & $\bar{x} \pm \mathrm{SE}$ & $95 \% \mathrm{CI}$ \\
\hline & & & & & & \\
Male solos & & & & & & \\
$\quad$ High hwee-oo & $8.0 \pm 0.20$ & $7.66-8.45$ & $26.0 \pm 0.73$ & $24.60-27.49$ & $35.1 \pm 0.69$ & $33.72-36.43$ \\
$\quad$ Low hwee-oo & $10.0 \pm 0.34$ & $9.31-10.64$ & $31.5 \pm 1.17$ & $29.20 \pm 33.81$ & $32.5 \pm 1.01$ & $30.49-34.44$ \\
Hwee-hwee & $11.1 \pm 0.68$ & $9.81-12.47$ & $31.4 \pm 2.04$ & $27.39-35.41$ & $36.9 \pm 1.27$ & $34.38-39.38$ \\
& & & & & & \\
Female solos & & & & & & \\
Chock & $6.8 \pm 0.59$ & $5.63-8.01$ & $43.6 \pm 3.19$ & $37.25-50.02$ & $94.9 \pm 43.07$ & $8.80-181.07$ \\
Chock-series & $5.0 \pm 0.07$ & $4.84-5.10$ & $1.9 \pm 0.01$ & $1.25-1.31$ & $172.4 \pm 18.12$ & $136.82-208.05$ \\
Kee-roo & $5.7 \pm 0.91$ & $3.93-7.57$ & $8.54 \pm 2.11$ & $4.33-12.76$ & $114.9 \pm 10.31$ & $94.23-135.57$ \\
Keck & $28 \pm 01.43$ & $25.22-30.86$ & $8.72 \pm 0.42$ & $7.89-9.55$ & $232.1 \pm 4.28$ & $223.71-240.52$ \\
$\quad$ Rasp $^{*}$ & $4.4 \pm 0.73$ & $2.84-5.89$ & $18.79 \pm 6.22$ & $5.71-31.86$ & $64.8 \pm 10.28$ & $43.25-86.44$ \\
\hline
\end{tabular}

3

$4 \quad$ *Keck and Rasp vocalizations were recognized as functional calls (alarm and excitement). See text for details. 